\title{
Primary Prevention of Type 2 Diabetes is Advancing towards the Mature Stage in Europe
}

Authors

Affiliations

\author{
J. Tuomilehto ${ }^{1,2,3}$, P. E. Schwarz ${ }^{4}$ \\ ${ }^{1}$ Hjelt Institute, Department of Public Health, University of Helsinki, Helsinki, Finland \\ 2 South Ostrobothnia Central Hospital, Seinäjoki, Finland \\ ${ }^{3}$ Spanish Diabetes Foundation, Madrid, Spain \\ ${ }^{4}$ Department of Medicine III, Prevention and Care of Diabetes, University of Dresden, Dresden, Germany
}

Bibliography

DOI http://dx.doi.org/

10.1055/s-0029-1241004

Horm Metab Res 2010; 42

(Suppl. 1): S1-S2 @ Georg

Thieme Verlag KG Stuttgart

New York · ISSN 0018-5043

\section{Correspondence}

Peter Schwarz M. D.

Department of Medicine III

University of Dresden

Fetscherstr. 74

01307 Dresden

Germany

Phone: + 493514582715

Fax: + 493514587319

peter.schwarz@

uniklinikum-dresden.de
Issues related to the prevention of type 2 diabetes (T2D) have become a major force in health care during the last decade. Although prevention of T2D is almost a matter of course today, the situation was very different only 25 years ago, that is, no serious attempts for T2D prevention existed back then [1]. Yet, diabetes has been one of the best-known chronic diseases during the past 4000 years.

Nowadays, while epidemiological transition has resulted in a dramatically improved life expectancy, in particular in developed countries, the prevalence of chronic noncommunicable diseases including T2D has exploded. Previously, daily life activities and the absence of motored transportation ensured the correct energy balance and physical fitness that also guaranteed good metabolic health. This was the situation still about 50 years ago. In addition, due to limited food supply in general, excessive energy intake was uncommon for most people. Therefore, obesity was not a major public health problem until recently. The modern "era of obesity and physical inactivity" really emerged with full might around the 1970s. Every epidemic has its roots. Accordingly, every mass epidemic must be tackled with mass interventions. T2D has its origins in a complex interplay between social, behavioural, genetic, and metabolic factors. These are not easy to control. Nevertheless, the history of public health has a plethora of examples to demonstrate how preventive measures can lead to the reduction of common diseases and their consequences. While today the news headlines manifestly report that some individuals have died from avian or swine flu, deaths due to diabetes that occur every $10 \mathrm{sec}-$ onds worldwide do not reach the threshold of news coverage.

It may not be possible to eradicate chronic noncommunicable diseases, but their burden can be reduced dramatically. Good examples are coronary heart disease, stroke, lung cancer, etc. From these actions to reduce the burden of noncommunicable diseases we have learned that successful prevention must be based on both populationbased actions targeted at the entire community and the high-risk approach targeted at individuals at the highest risk of a particular disease [2]. There is something old and something new that we need to consider. The old facts described by our ancient predecessor medical doctors emphasize the importance of healthy diet, physical activity, and social support. It would be naive to even think that these facts would not be applicable in the human population today, since our genes have not changed much during the past few thousand years. On the other hand, the environment where we live has changed drastically, but only during the last one or two centuries, most notably during the last 50 years.

Luckily, scientists have been alerted to this emerging epidemic of diabetes and considered actions that might help to prevent this epidemic growing further. In the beginning this was just a small effort by a few people [3], and even though the World Health Organisation (WHO) organised a Study Group Meeting on the prevention of diabetes and its complications in 1994 [4], WHO and its member states did virtually nothing to implement the recommendations of this expert group. It seems that developping an understanding as to how to establish effective prevention was left to the hands of individuals who volunteered to devote time and effort to find out how and to what extent T2D may be prevented [5].

Today, the situation looks much brighter for the prevention of T2D. First, research to establish the necessary data base for evidence-based prevention has accumulated large amounts of data from observational studies around the world. Second, simple and efficient risk scores for screening for T2D risk have been developed and used in a public health setting [6]. Third, randomised controlled trials have demonstrated that lifestyle in- 
tervention targeting main modifiable risk factors for T2D in high risk individuals is highly effective reducing the incidence of T2D by about $50 \%$ [7-9]. Fourth, nationwide or regional T2D prevention programmes have been set up in order to translate the research findings to the real-life settings - Finland was the first country to establish such a programme 10 years ago [10] followed by others [11].

These experiences have increased our understanding of the potential for the prevention of T2D, and also of obstacles in setting up T2D prevention in the community. Thus, it has been possible to collate this information in a systematic manner, which now appears in this journal. These include evidence-based guidelines on T2D prevention [12], a prevention toolkit [13], and a report on quality indicators in T2D prevention [14]. These have been developed within the IMAGE [15] project funded by the European Community and participating institutions. The information in these papers will represent a major further step in the effort to make T2D prevention a reality in Europe. It will now be the task of various stakeholders to take action as outlined in these documents. As estimated by the International Diabetes Federation, the number of T2D patients is likely to increase during the coming years, and maybe decades in Europe, but with the implementation of these recommendations now outlined it is anticipated that the increase of the T2D epidemic will be eventually controlled and the burden of diabetes gradually diminished. These recommendations should be integrated now into various national and international recommendations. Although these guidelines effectively target the European populations, it is obvious that much of them is also valid for many other parts of the world, at least with certain modifications.

There will be a lot of work involved in implementing these recommendations. Also, there is a need to continue systematic research into the aetiology, prevention, and management of T2D. In particular, translational research regarding the implementation of existing knowledge in public health management and clinical practice must be carried out. This is not possible without the proper research funding that should become available through various national and international funding sources. In any case, the future of T2D prevention has never been as bright as it is today. Early advocates of diabetes prevention including Dr. Elliot Joslin [16] would be surprised by this very remarkable development we are witnessing at the present time.

\section{Conflict of Interest}

$\nabla$

The IMAGE project (No 2006309) received funding from the European Union within the framework of the Public Health Programme (2003-2008). The networking process and the implementation of the IMAGE project results are supported by unrestricted grants from Bayer Health Care, Lilly, Merck, MSD Diabetes, The German Diabetes Foundation and Herbert-Quandt Foundation.

\section{References}

1 Tuomilehto J, Wolf E. Primary prevention of diabetes mellitus. Diabetes Care 1987; 10: 238-248

2 Puska P, Nissinen A, Tuomilehto J, Salonen JT, Koskela K, McAlister A Kottke TE, Maccoby N, Farquhar JW. The community-based strategy to prevent coronary heart disease: conclusions from the ten years of the North Karelia project. Annu Rev Public Health 1985; 6: 147-193

3 Knowler WC, Narayan KM, Hanson RL, Nelson RG, Bennett PH, Tuomilehto J, Schersten B, Pettitt DJ. Preventing non-insulin-dependent diabetes. Diabetes 1995; 44: 483-488

4 Prevention of diabetes mellitus. Report of a WHO Study Group. World Health Organ Tech Rep Ser 1994; 844: 1-100

5 Tuomilehto J, Tuomilehto-Wolf E, Zimmet P, Alberti KGMM, Knowler WC. Primary prevention of diabetes mellitus, 2nd edition. London: Wiley; 1997

6 Schwarz PE, Li J, Lindstrom J, Tuomilehto J. Tools for predicting the risk of type 2 diabetes in daily practice. Horm Metab Res 2009; 41: 86-97

7 Knowler WC, Barrett-Connor E, Fowler SE, Hamman RF, Lachin JM, Walker EA, Nathan DM. Reduction in the incidence of type 2 diabetes with lifestyle intervention or metformin. N Engl J Med 2002; 346: 393-403

8 Tuomilehto J. Counterpoint: Evidence-based prevention of type 2 diabetes: the power of lifestyle management. Diabetes Care 2007; 30 : 435-438

9 Tuomilehto J, Lindstrom J, Eriksson JG, Valle TT, Hamalainen H, IlanneParikka P, Keinanen-Kiukaanniemi S, Laakso M, Louheranta A, Rastas $M$, Salminen $V$, Uusitupa M. Prevention of type 2 diabetes mellitus by changes in lifestyle among subjects with impaired glucose tolerance. N Engl J Med 2001; 344: 1343-1350

10 Saaristo T, Peltonen M, Keinanen-Kiukaanniemi S, Vanhala M, Saltevo J, Niskanen L, Oksa H, Korpi-Hyovalti E, Tuomilehto J. National type 2 diabetes prevention programme in Finland: FIN-D2D. Int J Circumpolar Health 2007; 66: 101-112

11 Schwarz PE, Schwarz J, Schuppenies A, Bornstein SR, Schulze J. Development of a diabetes prevention management program for clinical practice. Public Health Rep 2007; 122: 258-263

12 Paulweber B, Valensi P, Lindström J, Lalic NM, Greaves CJ, McKee M, Kissimova-Skarbek K, Liatis S, Cosson E, Szendroedi J, Sheppard KE, Charlesworth K, Felton AM, Hall M, Rissanen A, Tuomilehto J, Schwarz PE, Roden $M$, for the Writing Group, on behalf of the IMAGE Study Group. A European evidence-based guideline for the prevention of type 2 diabetes. Horm Metab Res 2010; 42 (Suppl. 1): S3-S36

13 Lindström J, Neumann A, Sheppard KE, Gilis-Januszewska A, Greaves CJ, Handke U, Pajunen P, Puhl S, Pölönen A, Rissanen A, Roden M, Stemper T, Telle-Hjellset V, Tuomilehto J, Velickiene D, Schwarz PE, on behalf of the IMAGE Study Group. Take action to prevent diabetes - The IMAGE toolkit for the prevention of type 2 diabetes in Europe. Horm Metab Res 2010; 42 (Suppl. 1): S37-S55

14 Pajunen P, Landgraf R, Muylle F, Neumann A, Lindström J, Schwarz PE, Peltonen M, for the IMAGE Study Group. Quality indicators for the prevention of type 2 diabetes in Europe - IMAGE. Horm Metab Res 2010; 42 (Suppl. 1): S56-S63

15 Schwarz PE, Gruhl U, Bornstein SR, Landgraf R, Hall M, Tuomilehto J. The European perspective on diabetes prevention: development and implementation of a European guideline and training standards for diabetes prevention (IMAGE). Diab Vasc Dis Res 2007; 4: 353-357

16 Joslin E. The prevention of diabetes mellitus. JAMA 1921; 76: 79-84 